\title{
Shrinkage Effects of Using Fly Ash instead of Fine Aggregate in Concrete Mixtures
}

\author{
Dongsheng Zhang $\left(\mathbb{D}\right.$, Pengfei Han, Qiuning Yang ${ }^{(D)}$, and Mingjie Mao \\ School of Civil and Hydraulic Engineering, Ningxia University, Yinchuan 750021, China \\ Correspondence should be addressed to Mingjie Mao; maomjnxdx@163.com
}

Received 10 December 2019; Accepted 23 January 2020; Published 9 April 2020

Academic Editor: Tomasz Trzepieciński

Copyright (C) 2020 Dongsheng Zhang et al. This is an open access article distributed under the Creative Commons Attribution License, which permits unrestricted use, distribution, and reproduction in any medium, provided the original work is properly cited.

\begin{abstract}
China is the world's largest emitter of fly ash, an industrial by-product of coal combustion. Motivated towards greener development, China's engineering industries must determine how to effectively utilize this by-product, while ensuring environmental and public safety protections. This study investigated the use of fly ash instead of fine aggregate in concrete mixtures with a focus on concrete shrinkage. A series of experiments were performed in which fly ash substitution levels, water-binder ratios, and ambient humidities were each respectively and exclusively varied to determine changes in the concrete's drying and autogenous shrinkages. Experimental results indicated that the substitution of fly ash consistently decreased the drying shrinkage relative to ordinary concrete; a substitution level of $25 \%$ optimally reduced the drying shrinkage by $20.81 \%$. A substitution level of $15 \%$ decreased the autogenous shrinkage relative to ordinary concrete, whereas higher levels $(25,35$, and $45 \%)$ increased it. Ambient humidities also affected the concrete shrinkage, but the water-to-binder ratio effects were negligible. Drying shrinkage largely occurred before $28 \mathrm{~d}$, whereas autogenous shrinkage continued after $28 \mathrm{~d}$. Based on these experimental results, we evaluated common theoretical shrinkage models and subsequently developed a modified shrinkage model for application to concrete containing fly ash as fine aggregate.
\end{abstract}

\section{Introduction}

China's abundant coal resources account for more than $70 \%$ of its total annual energy consumption [1]. In 2016, thermal power generation totalled 4,395.8 billion $\mathrm{kWh}$ in China, which was equivalent to $74.37 \%$ of the nation's total power generation. This massive reliance on coal has made China the world's largest emitter of fly ash, an industrial byproduct of coal combustion [2]. Fly ash emission levels have continued to increase over time. In 2009, China's fly ash emission was 375 million tons but rose to approximately 600 million tons in 2016. Fly ash is a harmful industrial byproduct that pollutes the environment and adversely affects human health. Trace elements contained in coal fly ash might also contaminate the soil [3-5]. Energy industries in China and around the world seeking to move towards greener development must first determine how to effectively utilize the excessive amounts of fly ash emitted during coal combustion, while ensuring environmental and public safety protections.

Historically, fly ash has been substituted for up to $30-40 \%$ of the cementitious materials in concrete mixtures [6-9]. However, when fly ash is used as an alternative to cement, the concrete's early strength is slow to develop, limiting the viability of this type of utilization [10]. Some studies have indicated that a more viable utilization of fly ash is as a substitute for the fine aggregate in concrete mixtures $[4,11]$. Contemporary research regarding concrete with fly ash as the fine aggregate (CFA) has focused on the concrete's mechanical properties [12-15], broadly confirming that the compressive and flexural strengths of CFA are superior to ordinary concrete. Few studies have considered the durability of CFA [15-17]. This lack of knowledge regarding CFA durability, and, in particular, its volume stability, limits its practical engineering applications. For example, concrete cracking caused by volume shrinkage may seriously affect a 
building structural service life and its safety. A greater understanding of CFA durability, including volume stability, is therefore required to support a greener utilization of fly ash by energy industries.

Shrinkage is often used to characterize the volume stability of concrete. Concrete shrinkage refers to its volume shrinkage due to changes in moisture, chemical reactions, and temperature reduction [18]. Three types of concrete shrinkage have been identified: (1) plastic shrinkage that occurs at the initial stage of pouring, (2) autogenous shrinkage caused by cement hydration, and (3) drying shrinkage caused by water evaporation. Previous research regarding shrinkage in cement-based materials focused singularly on shrinkage outcomes without adequate consideration of contributing factors [19-22]. In fact, a complex relationship exists between a concrete's shrinkage, strength, and workability and its mix proportion.

To advance the state of knowledge regarding CFA durability and ultimately support greener utilization of coal combustion by-products, we investigated the use of fly ash instead of fine aggregate in concrete mixtures with a focus on concrete shrinkage. In this study, we performed a series of experiments varying only fly ash substitution levels $(0,15$, 25,35 , and $45 \%$ ) initially and then varying water-binder ratios and ambient humidities to determine the concrete's drying and autogenous shrinkages. The shrinkage effect magnitudes for each of these factors was determined using range analysis and compositional ratios in an effort to optimize the concrete mix design and minimize CFA shrinkage. We next used these experimental results to evaluate common theoretical shrinkage models and subsequently develop a modified shrinkage model for application to concrete containing fly ash as the fine aggregate.

\section{Materials and Methods}

2.1. Materials. In this study, the concrete mixtures used for experimentation comprised varying amounts of ordinary Portland cement, crushed stone, natural medium sand as the fine aggregate, Class III fly ash, and powdered naphthalene as the water reducing agent. The ordinary Portland cement (PO 42.5R) was obtained from Ningxia Saima Industry Co., Ltd. The continuous crushed stone had a particle size of approximately $5-31.5 \mathrm{~mm}$, a mud content of $0.6 \%$, a crushing index of $10.2 \%$, and a needle particle content of $9.7 \%$. The natural medium sand had a fineness modulus of 2.71 and a mud content of $0.43 \%$. Class III fly ash had a density of $2.06 \mathrm{~g} / \mathrm{cm}^{3}$, a fineness of $34.3 \%$, and a loss on ignition of $5.74 \%$. Table 1 details the chemical composition of Class III fly ash used in this study.

2.2. Experimental Design. Before preparing any of the concrete specimens for testing, we first developed a careful experimental design that supported both single-factor and orthogonal analyses. First, single-factor analyses were performed to determine the effects of varying fly ash substitution levels $(0,15,25,35$, and $45 \%)$ on the CFA's drying and autogenous shrinkages under constant temperature
TABLE 1: Chemical composition of Class III fly ash (\%).

\begin{tabular}{lcccccccc}
\hline $\mathrm{SiO}_{2}$ & $\mathrm{Al}_{2} \mathrm{O}_{3}$ & $\mathrm{CaO}$ & $\mathrm{Fe}_{2} \mathrm{O}_{3}$ & $\mathrm{MgO}$ & $\mathrm{SO}_{3}$ & $\mathrm{P}_{2} \mathrm{O}_{5}$ & $\mathrm{Na}_{2} \mathrm{O}$ & $\mathrm{K}_{2} \mathrm{O}$ \\
\hline 50.35 & 29.65 & 5.85 & 6.61 & 1.83 & 1.72 & 1.13 & 0.335 & 2.11 \\
\hline
\end{tabular}

$\left(20 \pm 2^{\circ} \mathrm{C}\right)$ and relative humidities $(60 \pm 5 \%)$. Table 2 details the corresponding material quantities used in the different concrete mixtures, corresponding to each of the five fly ash substitution levels (G1-G5).

Next, Three-factor three-level orthogonal analyses were performed to determine the contributing effects of the waterbinder ratio and ambient humidity on the CFA's shrinkage. Specifically, different concrete mixtures were developed with varying fly ash substitution levels of 15,25 , and 35\%; waterbinder ratios of $0.4,0.5$, and 0.6 ; and ambient humidities of 0 (sealed), 60, and 100\% relative humidity (RH) (based on previous research results [14], the optimal substitute for fly ash to replace fine aggregate is known to be $25 \%$ in the design of orthogonal experimental schemes; thus, a fly ash substitution level of $45 \%$ was not used in this case). Table 3 details the corresponding material quantities used in the different concrete mixtures, corresponding to each of the nine varying factor combinations (S1-S9).

For each type of analysis, the quantity of fly ash per cubic meter was calculated as follows, using a $15 \%$ fly ash substitution level as an example:

$$
M_{\mathrm{FA}}=\frac{M_{S} \cdot 15 \% \cdot \rho_{\mathrm{FA}}}{\rho_{S}},
$$

where $M_{\mathrm{FA}}$ and $\rho_{\mathrm{FA}}$ are the unit quantity and density of fly ash, and $M_{s}$ and $\rho_{s}$ are the unit quantity and density of the fine aggregate.

2.3. Concrete Specimen Preparation and Casting. With this study's experimental design carefully developed, we next prepared and cast the various concrete specimens for testing in accordance with the Chinese Standard for Test Method of Mechanical Properties on Ordinary Concrete (GB/T 500812002) [23]. First, we mixed the fly ash, fine aggregate, and cement in a concrete mixer for $30 \mathrm{~s}$. Next, we sequentially added the water reducer, half of the total water quantity, and the coarse aggregate and stirred for $2 \mathrm{~min}$. The remaining water was gradually added to the mixture. The final mixture was stirred for an additional $1 \mathrm{~min}$ to ensure an even distribution of materials and was subsequently placed and vibrated in a $100 \times 100 \times 515 \mathrm{~mm}$ shrinkage test block mould. Figure 1 depicts the concrete shrinkage test block mould used in this study. This process was repeated for each of the mix designs detailed in Section 2.2, with three moulds produced per design.

After $24 \mathrm{~h}$, the moulds were removed. The concrete test specimens were initially placed in a standard curing environment for $3 \mathrm{~d}$ and then moved to a temperature $\left(20 \pm 2^{\circ} \mathrm{C}\right)$ and humidity $(60 \pm 5 \% \mathrm{RH})$ controlled environment for the remainder of the cure time. The concrete test specimens were positioned with gaps between them to allow for proper air circulation. To obtain the $0 \% \mathrm{RH}$ for select specimens used in the orthogonal analyses, the concrete test specimens were sealed with plastic film and waterproof tape. This subset 
TABLE 2: Concrete mixtures used for single-factor analyses.

\begin{tabular}{|c|c|c|c|c|c|c|c|c|}
\hline \multirow[b]{2}{*}{ Mixture } & \multicolumn{2}{|c|}{ Fly ash } & \multirow[b]{2}{*}{$\begin{array}{l}\text { Sand } \\
\left(\mathrm{kg} / \mathrm{m}^{3}\right)\end{array}$} & \multirow[b]{2}{*}{$\begin{array}{l}\text { Gravel } \\
\left(\mathrm{kg} / \mathrm{m}^{3}\right)\end{array}$} & \multirow[b]{2}{*}{$\begin{array}{l}\text { Cement } \\
\left(\mathrm{kg} / \mathrm{m}^{3}\right)\end{array}$} & \multirow[b]{2}{*}{$\begin{array}{l}\text { Water } \\
\left(\mathrm{kg} / \mathrm{m}^{3}\right)\end{array}$} & \multirow[b]{2}{*}{$\begin{array}{l}\text { Water-binder } \\
\quad \text { ratio }\end{array}$} & \multirow[b]{2}{*}{$\begin{array}{l}\text { Water reducing agent } \\
\qquad\left(\mathrm{kg} / \mathrm{m}^{3}\right)\end{array}$} \\
\hline & $\begin{array}{c}\text { Percentage } \\
(\%)\end{array}$ & $\begin{array}{l}\text { Quantity } \\
\left(\mathrm{kg} / \mathrm{m}^{3}\right)\end{array}$ & & & & & & \\
\hline G1 & 0 & 0.00 & 840.30 & & & & & 6.18 \\
\hline G2 & 15 & 99.87 & 714.26 & & & & & 7.72 \\
\hline G3 & 25 & 166.44 & 630.23 & 1027.03 & 308.93 & 185.41 & 0.6 & 7.72 \\
\hline G4 & 35 & 233.02 & 546.20 & & & & & 9.27 \\
\hline G5 & 45 & 299.60 & 462.17 & & & & & 9.27 \\
\hline
\end{tabular}

TABLE 3: Concrete mixtures used for orthogonal analyses.

\begin{tabular}{|c|c|c|c|c|c|c|c|c|c|}
\hline \multirow[b]{2}{*}{ Mixture } & \multicolumn{2}{|c|}{ Fly ash } & \multirow[b]{2}{*}{$\begin{array}{c}\text { Sand } \\
\left(\mathrm{kg} / \mathrm{m}^{3}\right)\end{array}$} & \multirow[b]{2}{*}{$\begin{array}{l}\text { Gravel } \\
\left(\mathrm{kg} / \mathrm{m}^{3}\right)\end{array}$} & \multirow[b]{2}{*}{$\begin{array}{l}\text { Cement } \\
\left(\mathrm{kg} / \mathrm{m}^{3}\right)\end{array}$} & \multirow[b]{2}{*}{$\begin{array}{l}\text { Water } \\
\left(\mathrm{kg} / \mathrm{m}^{3}\right)\end{array}$} & \multirow[b]{2}{*}{$\begin{array}{c}\text { Water- } \\
\text { binder ratio }\end{array}$} & \multirow[b]{2}{*}{$\begin{array}{l}\text { Water reducing } \\
\text { agent }(\mathrm{kg} /)\end{array}$} & \multirow{2}{*}{$\begin{array}{c}\text { Ambient } \\
\text { humidity } \\
(\% \mathrm{RH})\end{array}$} \\
\hline & $\begin{array}{c}\text { Percentage } \\
(\%)\end{array}$ & $\begin{array}{l}\text { Quantity } \\
\left(\mathrm{kg} / \mathrm{m}^{3}\right)\end{array}$ & & & & & & & \\
\hline S1 & $15(1)$ & 106.43 & 761.20 & 1094.52 & 329.23 & 131.88 & $0.4(1)$ & 9.88 & 0 (sealed) (1) \\
\hline $\mathrm{S} 2$ & $15(1)$ & 103.06 & 737.06 & 1059.82 & 318.79 & 159.40 & $0.5(2)$ & 9.57 & $60(2)$ \\
\hline S3 & $15(1)$ & 99.87 & 714.26 & 1027.03 & 308.93 & 185.41 & $0.6(3)$ & 9.27 & $100(3)$ \\
\hline S4 & $25(2)$ & 177.38 & 671.64 & 1094.52 & 329.23 & 131.88 & $0.4(1)$ & 9.88 & $100(3)$ \\
\hline S5 & $25(2)$ & 171.75 & 650.35 & 1059.82 & 318.79 & 159.40 & $0.5(2)$ & 9.57 & 0 (sealed) (1) \\
\hline S6 & $25(2)$ & 166.44 & 630.23 & 1027.03 & 308.93 & 185.41 & $0.6(3)$ & 9.27 & $60(2)$ \\
\hline S7 & $35(3)$ & 248.33 & 582.09 & 1094.52 & 329.23 & 131.88 & $0.4(1)$ & 11.52 & $60(2)$ \\
\hline S8 & $35(3)$ & 240.46 & 563.64 & 1059.82 & 318.79 & 159.40 & $0.5(2)$ & 11.16 & $100(3)$ \\
\hline S9 & $35(3)$ & 233.02 & 546.20 & 1027.03 & 308.93 & 185.41 & $0.6(3)$ & 10.81 & 0 (sealed) (1) \\
\hline
\end{tabular}

Note. Parenthetical numbers (e.g., (1), (2), and (3)) reflect the three levels for each factor considered during analysis.

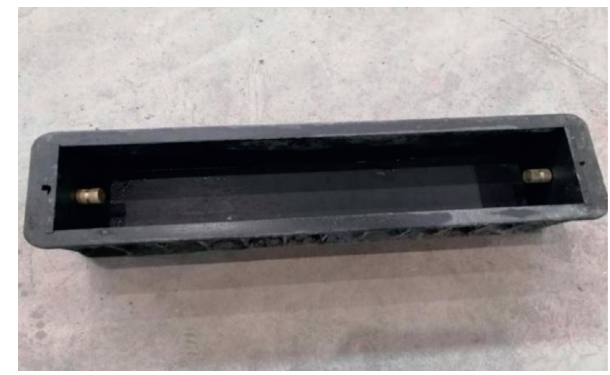

FIgURE 1: Concrete shrinkage test block mould.

of specimens was placed on an overhead waterproof shelf. Figure 2 depicts the positioning of the concrete test specimens during curing.

2.4. Concrete Shrinkage Test Method. After the concrete test specimens were fully prepared, we performed concrete shrinkage tests in accordance with the Chinese Standard for Test Method of Long-term Performance and Durability of Ordinary Concrete (GB/T 50082-2009) [24]. The length of each concrete test specimen was measured and recorded immediately after the mould was removed and after 1, 3, 7, $14,28,45,60,90,120,150$, and $180 \mathrm{~d}$.

Following the specific test procedures, we first calibrated the standard bar against the dial gauge zero point and repeated this zero point calibration after every 2-3 specimen measurements. Each specimen was secured on the shrinking expander for measurement and marked such that the same orientation was maintained in repeated measurements. To minimize measurement error, each specimen was measured
2-3 times, with the average used as the shrinkage value for the specimen. Shrinkage measurements were further averaged across the three concrete test specimens from the same mix design to produce an average shrinkage value for the concrete mixture.

Concrete shrinkage was expressed proportionally as follows:

$$
\varepsilon_{s t}=\frac{L_{0}-L_{t}}{L_{b}}
$$

where $\varepsilon_{s t}$ is the shrinkage rate at time $t(\mathrm{~d})$ ( $t$ begins after the initial length of the specimen is measured), $L_{0}$ is the initial length of the specimen ( $\mathrm{mm}), L_{t}$ is the length of the specimen at time $t(\mathrm{~mm})$, and $L_{b}$ is the measurement scale length of the specimen $(\mathrm{mm})$.

2.5. Theoretical Shrinkage Model Evaluation. Concrete shrinkage occurs gradually over an extended period of time, limiting the potential for empirical assessments in practical engineering applications. Instead, we rely upon theoretical models to predict concrete shrinkage based on various factors. Three of the most commonly applied theoretical shrinkage models include the (1) Comité Européen du Béton (European Committee for Concrete)-Fédération Internationale de la Précontrainte (International Federation for Prestressing) Model Code 1990 (CEB-FIP 90) model [25], (2) American Concrete Institute 209R (ACI 209R) model [26], and (3) Gardner and Lockman 2000 (GL 2000) model [27]. Each of these models was developed based on ordinary concrete applications. To determine the validity of these models for CFA applications, we compared the predicted 


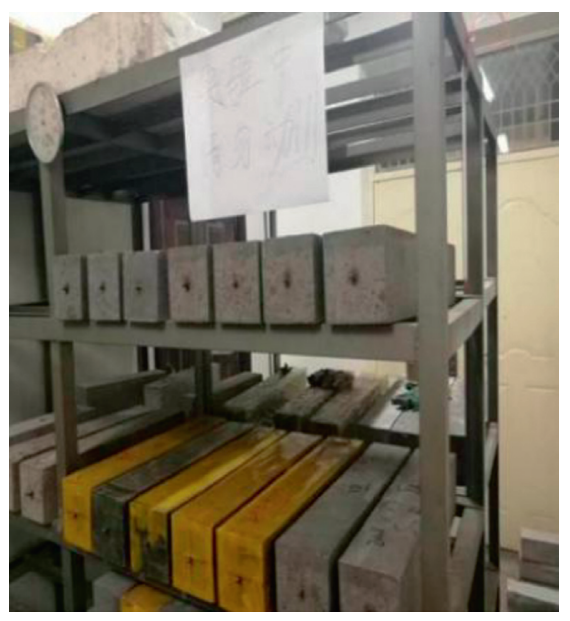

(a)

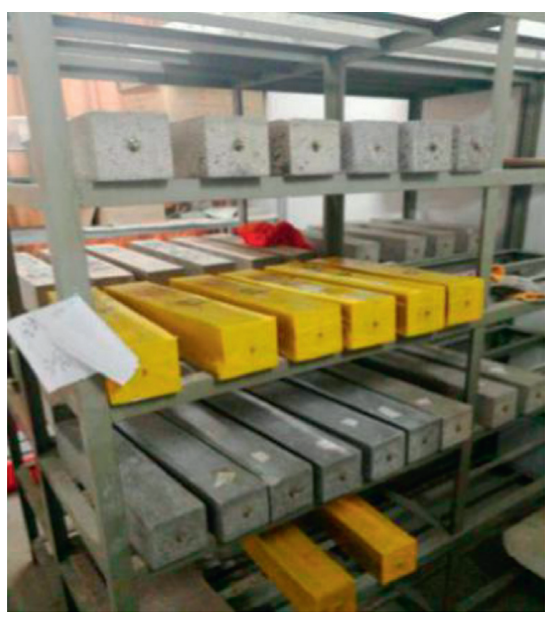

(b)

Figure 2: Positioning of concrete test specimens during curing.

concrete shrinkage values from the CEB-FIP 90, ACI 209R, and GL 2000 models with the observed concrete shrinkage values obtained during this study's experimentation. Based on these results, we subsequently modified the most accurate of these conventional shrinkage models to further improve its applicability for CFA.

\section{Results and Discussion}

\subsection{Experimental Results}

3.1.1. Shrinkage Effects of Varying Fly Ash Substitution Levels. Figure 3 depicts the effects of varying fly ash substitution levels $(0,15,25,35$, and $45 \%)$ on the CFA's drying shrinkage rate under constant temperature $\left(20 \pm 2^{\circ} \mathrm{C}\right)$ and relative humidities $(60 \pm 5 \%)$. Based on these single-factor analysis results, the substitution of fly ash consistently decreased drying shrinkage relative to ordinary concrete (with $0 \%$ fly ash) over time. A substitution level of $25 \%$ optimally reduced drying shrinkage by $20.81 \%$. At $180 \mathrm{~d}$, the shrinkage rates for the $25 \%$ and $0 \%$ fly ash specimens were $293.28 \times 10^{-6}$ and $370.06 \times 10^{-6}$, respectively.

Similar to volcanic ash, fly ash generates hydrated calcium carbonate and water-hydraulic calcium aluminate, which fill a portion of the water-retaining voids, limiting shrinkage [13]. In addition, fly ash can effectively replace a portion of the fine aggregate, resulting in a microaggregate effect [28]. Fly ash contains many small-sized glass bead and crumb particles that are evenly distributed inside the concrete. In the slurry, the capillary pores are filled by these particles, significantly enhancing the internal compactness of the concrete and limiting its shrinkage to some extent. If the fly ash content is too high, the microaggregate effect-which is dependent upon the full integration of the fly ash into the internal material structure matrix-decreases [29]. The results of this study were consistent with this phenomenon; higher rates of shrinkage were observed for concrete mixtures containing 35 and $45 \%$ fly ash instead of fine aggregate.

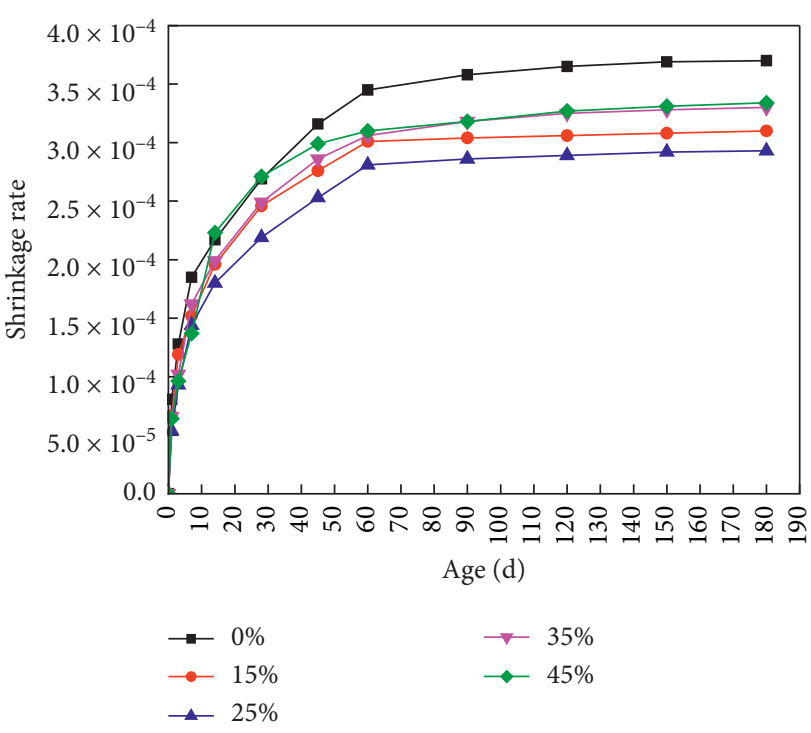

Figure 3: Effects of varying fly ash substitution levels $(0,15,25,35$, and $45 \%)$ on the CFA's drying shrinkage rate under constant temperature $\left(20 \pm 2^{\circ} \mathrm{C}\right)$ and relative humidities $(60 \pm 5 \%)$.

Figure 4 depicts the effects of varying fly ash substitution levels $(0,15,25,35$, and $45 \%)$ on the CFA's autogenous shrinkage rate under constant temperature $\left(20 \pm 2^{\circ} \mathrm{C}\right)$ and relative humidities $(60 \pm 5 \%)$. Previous studies found that a CFA's autogenous shrinkage decreased as fly ash content increased [30, 31]. In this study, however, higher fly ash substitution levels $(25,35$, and $45 \%)$ resulted in higher shrinkage rates relative to the ordinary concrete. Only the concrete mixture containing $15 \%$ fly ash instead of fine aggregate resulted in a lower shrinkage rate. When fly ash is used instead of fine aggregate, the amount of cement in the concrete mixture remains constant. Thus, the CFA has the same cement hydration as ordinary concrete, but the secondary hydration reaction from the fly ash increases volume shrinkage. Combined with the volcanic ash and 


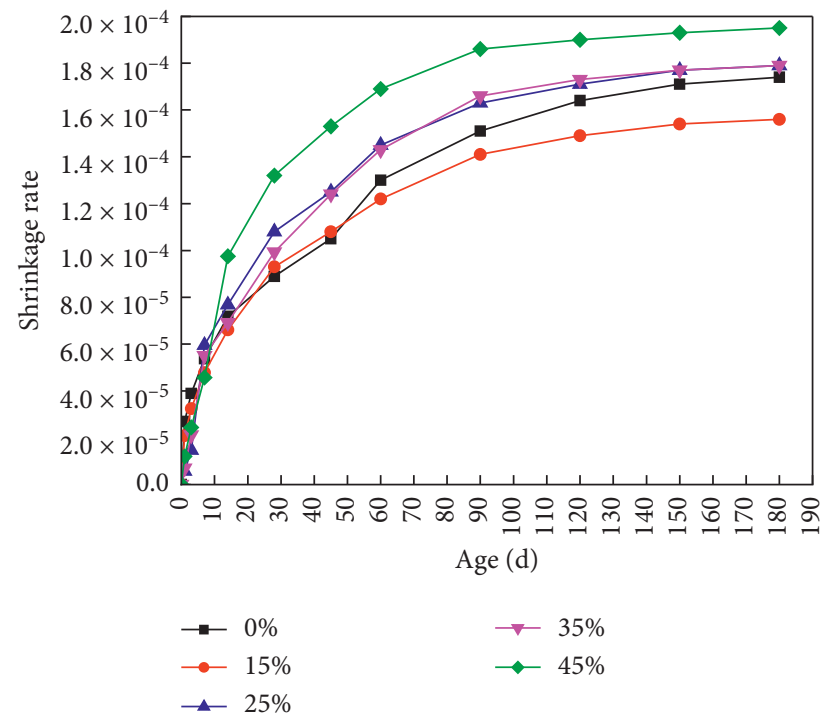

FIGURE 4: Effects of varying fly ash substitution levels (0, 15, 25, 35, and $45 \%$ ) on the CFA's autogenous shrinkage rate under constant temperature $\left(20 \pm 2^{\circ} \mathrm{C}\right)$ and relative humidities $(60 \pm 5 \%)$.

microaggregate effects of fly ash, these results suggest that lower levels of fly ash instead of fine aggregate may be beneficial in limiting concrete shrinkage.

Drying and autogenous shrinkages developed at different rates over time. Drying shrinkage largely occurred before $28 \mathrm{~d}$, while autogenous shrinkage continued after $28 \mathrm{~d}$. At $28 \mathrm{~d}$, the drying shrinkage accounted for approximately $72-82 \%$ of the final shrinkage value for each concrete mixture, while the autogenous shrinkage accounted for approximately 51-67\%. Shrinkage results from the loss of moisture inside the concrete. Porosity increases, effecting cohesion in the concrete and reducing its volume. Moisture loss occurs during the hydration reaction of the cementitious materials inside the concrete and through dispersal into the air [17]. Both mechanisms of moisture loss contribute to drying shrinkage, while autogenous shrinkage is primarily caused by the hydration reaction of the cementitious materials. Based on this study's results, the shrinkage effects from the hydration reaction of the cementitious materials occurred more rapidly than the shrinkage effects from dispersal into the air.

3.1.2. Shrinkage Effects of Varying Fly Ash Substitution Levels, Water-Binder Ratios, and Ambient Humidities. Figure 5 presents the effects of varying fly ash substitution levels, water-binder ratios, and ambient humidities (reflected as S1-S9 concrete mixtures) on the CFA's shrinkage rate. Based on these orthogonal analysis results, shrinkage occurred rapidly up to $14 \mathrm{~d}$ and then continued to increase more gradually. Differences in shrinkage rates among the various concrete mixtures were most apparent at $28 \mathrm{~d}$ when the $\mathrm{Ca}(\mathrm{OH})_{2}$ content in the hydration products of the composite cementitious materials spikes [32]. The pozzolanic reaction that occurs between the fly ash and the hydration product $\left[\mathrm{Ca}(\mathrm{OH})_{2}\right]$ consumes much of the internal water content $[33,34]$. This reaction subsequently results in a sharp

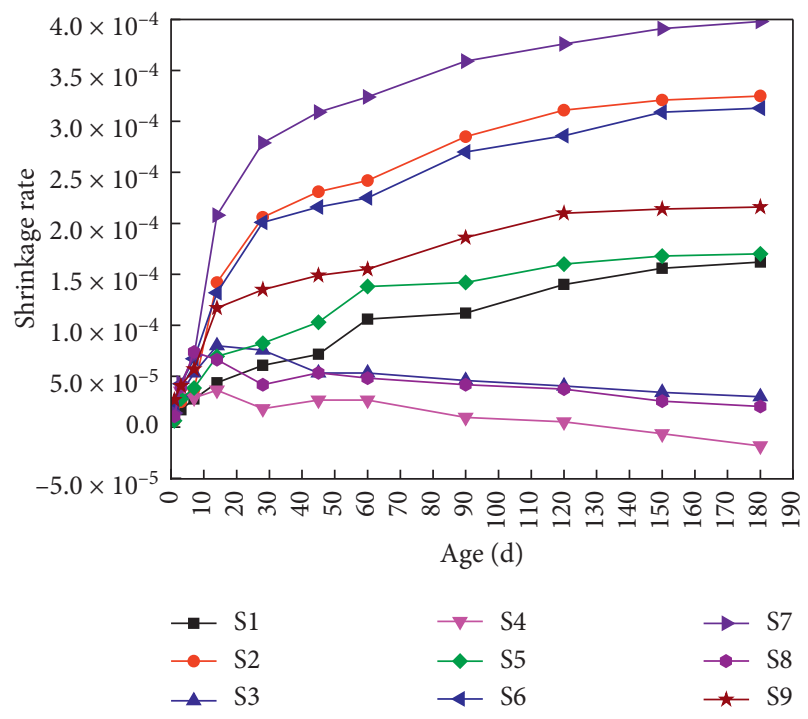

FIGURE 5: Effects of varying fly ash substitution levels, water-binder ratios, and ambient humidities (reflected as S1-S9 concrete mixtures) on the CFA's shrinkage rate.

decrease in the internal moisture of the concrete, affects its internal cohesive force, and causes large shrinkage deformation. Early-stage concrete has a lower strength and ability to resist deformation.

Next, we used range analysis to determine the contributing effects of the fly ash substitution levels, waterbinder ratios, and ambient humidities on the CFA's shrinkage rate. The range reflects the difference between each of the factor levels; a greater difference suggests a greater effect. Figure 6 shows the shrinkage rate range across different fly ash substitution levels, water-binder ratios, and ambient humidities. Based on these results, ambient humidities exhibited the greatest effect on CFA shrinkage. Consistent with the single-factor analysis results, fly ash substitution levels also affected CFA shrinkage because of its volcanic ash and microaggregate effects that decrease the concrete's internal porosity and limit concrete shrinkage. The water-to-binder ratio had negligible effect.

Differences in the shrinkage rate range were small among each of the factors up to $14 \mathrm{~d}$. After $14 \mathrm{~d}$, the effects of ambient humidity on the CFA's shrinkage were more obvious. Up to $14 \mathrm{~d}$, concrete shrinkage was mainly caused by the secondary hydration reaction of the fly ash and hydration product $\left[\mathrm{Ca}(\mathrm{OH})_{2}\right]$. After $14 \mathrm{~d}$, the effects of this secondary hydration reaction decreased and shrinkage instead was caused by the dispersal of moisture into the air. It is during this phase that the curing environment and associated ambient humidity plays a decisive role.

At $180 \mathrm{~d}$, the effect of the water-binder ratio on CFA shrinkage was negligible. Shrinkage is mainly caused by water loss from the pore, with pore radii of $1-10 \mathrm{~nm}$ [35]. For ordinary concrete, a low water-binder ratio suggests a higher volume of binding material that enhances the internal compactness of the concrete and limits its shrinkage.

Figures 7 and 8 show the effects of varying fly ash substitution levels and ambient humidities on the CFA's 


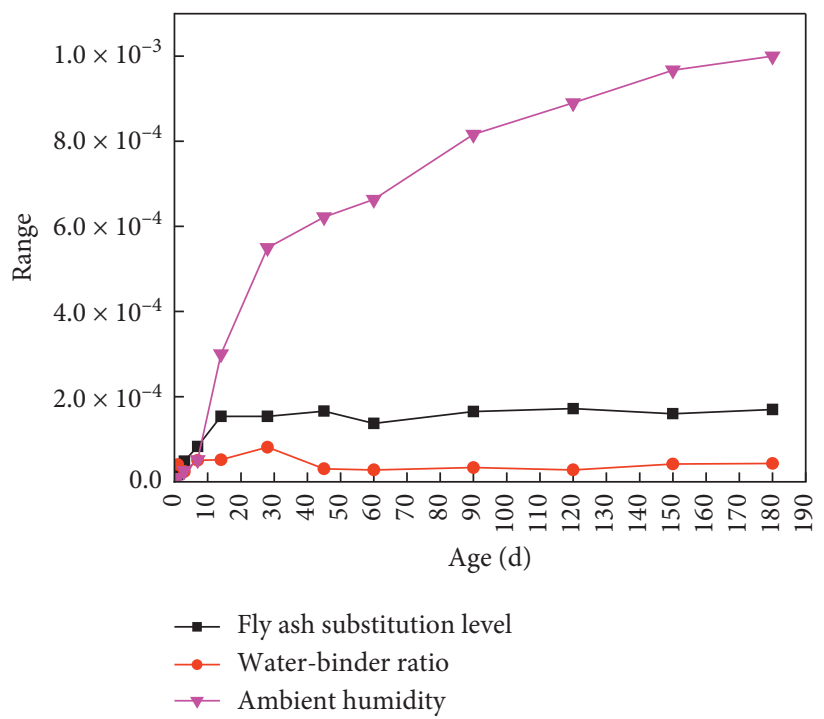

FIGURE 6: Shrinkage rate range across different fly ash substitution levels, water-binder ratios, and ambient humidities.

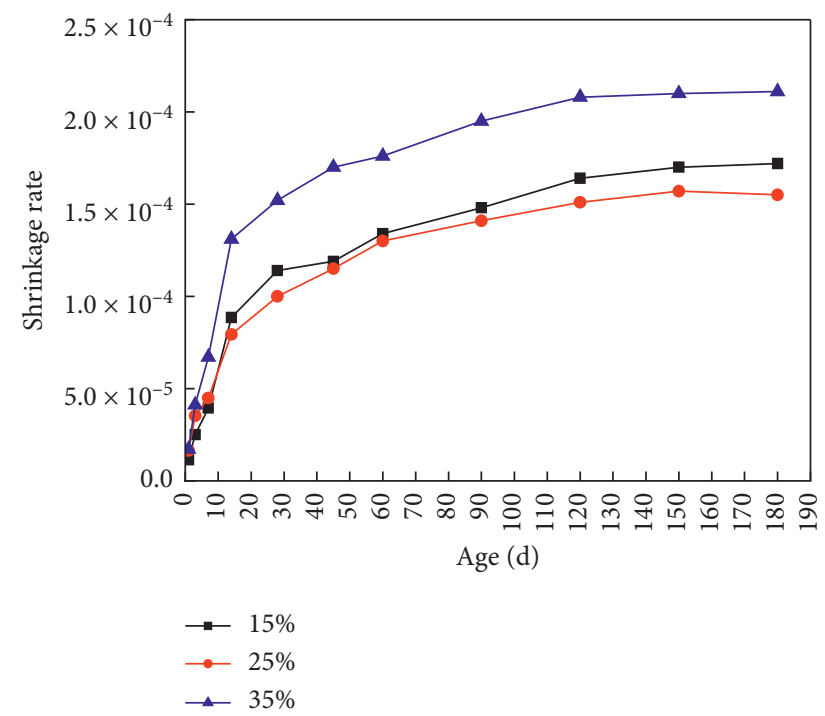

FIGURE 7: Effects of varying fly ash substitution levels on the CFA's shrinkage rate.

shrinkage rate, respectively. Consistent with the singlefactor analysis results regarding drying shrinkage, CFA shrinkage was minimized when the fly ash content was $25 \%$. Comparatively, CFA shrinkage was minimized when the ambient humidity was $100 \%$ RH. Higher relative humidities result in lower water losses and shrinkages. At $100 \% \mathrm{RH}$, concrete experiences a wet expansion deformation in its later stages, which is much smaller than the drying shrinkage [36]. At $0 \% \mathrm{RH}$ (sealed), the concrete was prevented from exchanging moisture with the surrounding environment, limiting any deformation to autogenous shrinkage. Thus, concrete test specimens cured at $0 \% \mathrm{RH}$ (sealed) experienced less shrinkage than those cured at $60 \%$ RH.

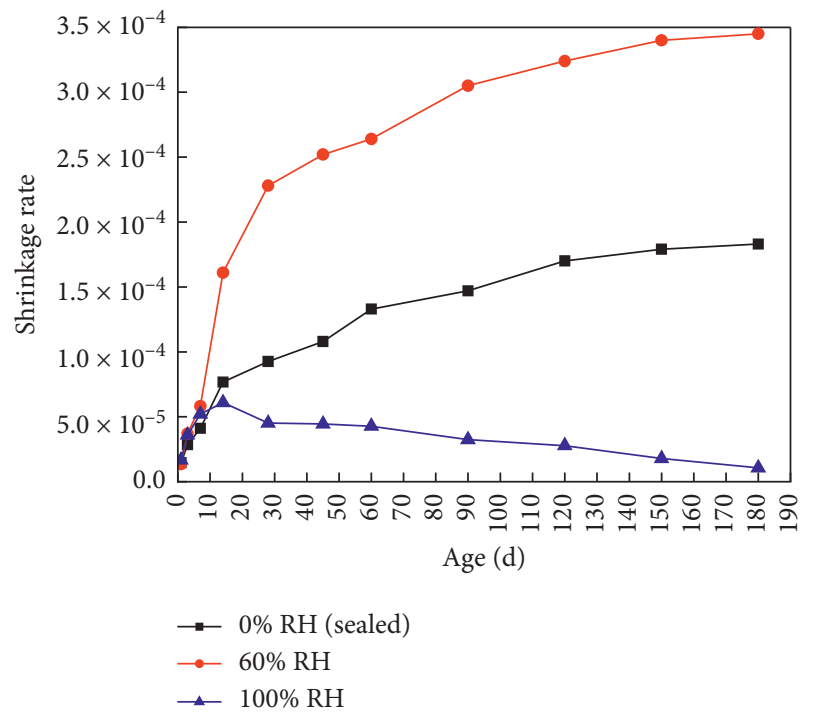

FIgURE 8: Effects of varying ambient humidities on the CFA's shrinkage rate.

\subsection{Theoretical Shrinkage Model Evaluation Results}

3.2.1. Comparison among Predicted and Observed Concrete Shrinkage Values. To determine the validity of conventional shrinkage models for CFA applications, we compared the predicted concrete shrinkage values from the CEB-FIP 90, ACI 209R, and GL 2000 models with the observed concrete shrinkage values obtained during this study's experimentation for concrete mixtures containing 15, 25, 35, and $45 \%$ fly ash instead of fine aggregate. Figure 9 shows the results of these comparisons.

Based on these results, it is clear that the ACI 209R and GL 2000 models both underestimated CFA shrinkage in the early stages and overestimated CFA shrinkage in the later stages. In each case, the predicted results deviated greatly 

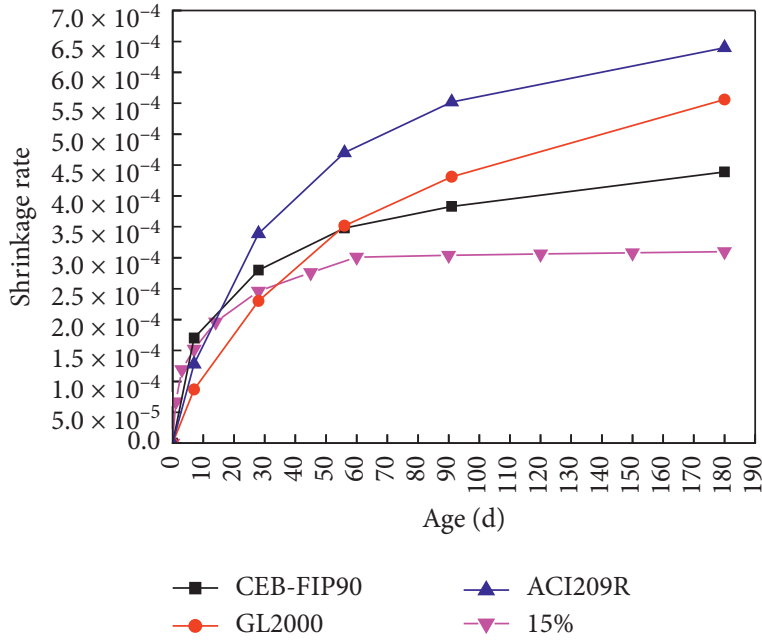

(a)

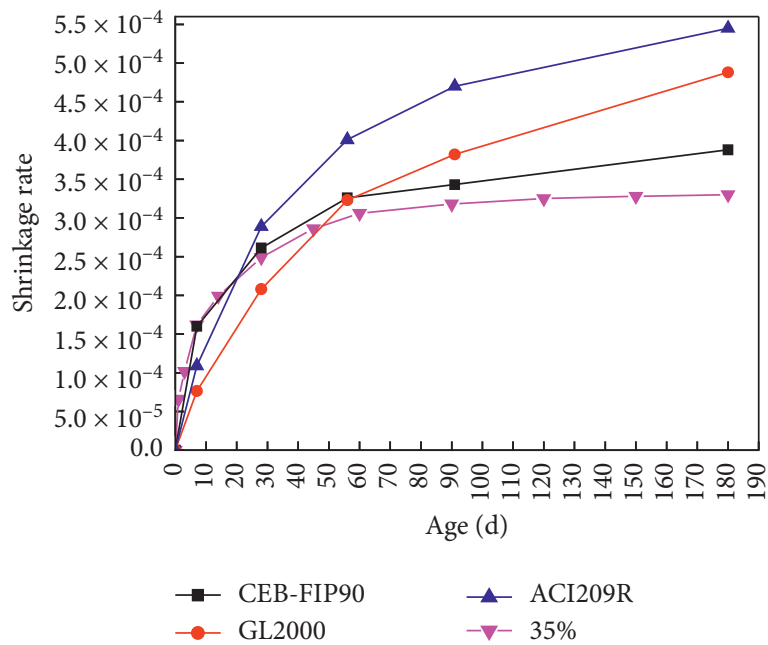

(c)
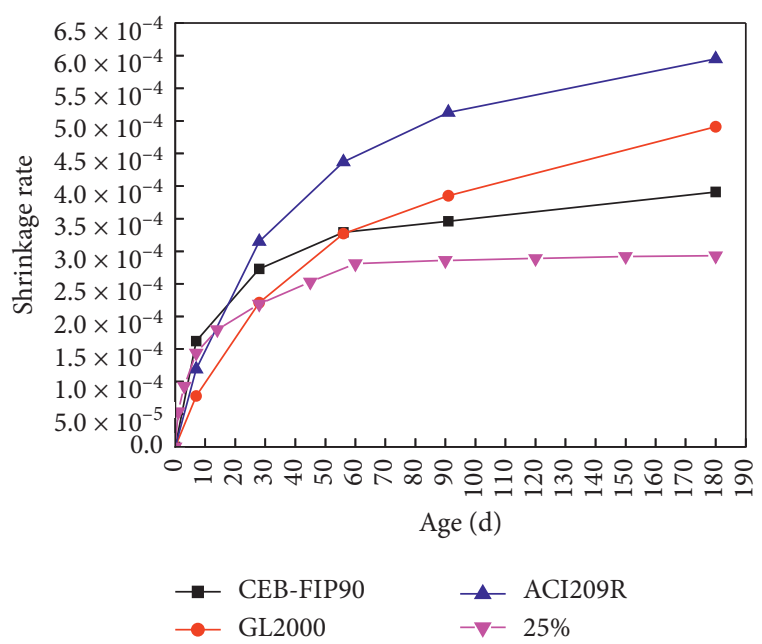

(b)

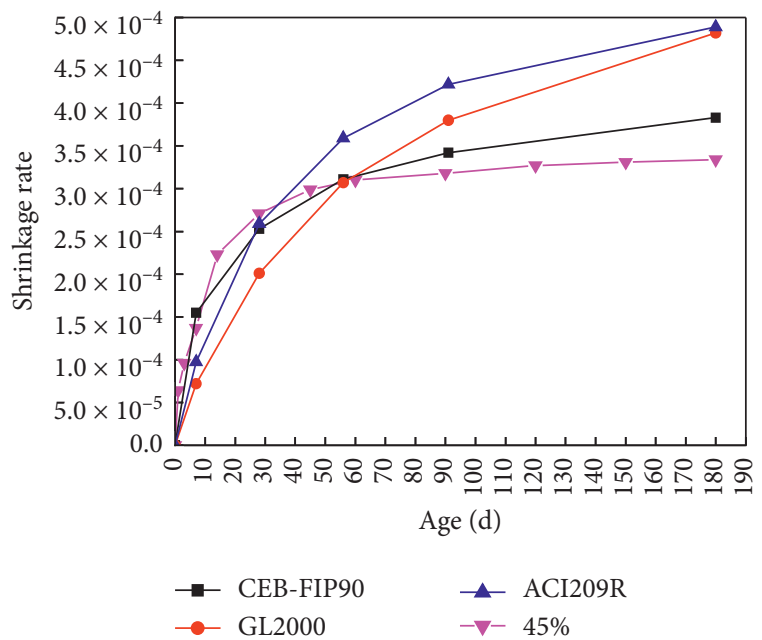

(d)

FIGURE 9: Comparison among the predicted concrete shrinkage values from the CEB-FIP 90, ACI 209R, and GL 2000 models and the observed concrete shrinkage values obtained during this study's experimentation: (a) $15 \%$ fly ash; (b) $25 \%$ fly ash; (c) $35 \%$ fly ash; (d) $45 \%$ fly ash.

from the observed results. Comparatively, the CEB-FIP 90 model had the highest prediction accuracy relative to the observed CFA shrinkage values. For the concrete mixtures containing 35 and $45 \%$ fly ash instead of fine aggregate, the CEB-FIP 90 model's accuracy is particularly high.

3.2.2. Modified Theoretical Shrinkage Model for CFA. With the CEB-FIP 90 model exhibiting the highest prediction accuracies, we subsequently modified this conventional model to further improve its applicability for CFA. The CEB-FIP 90 shrinkage model can be formulated using the following set of equations:

$$
\begin{aligned}
\varepsilon_{c s}\left(t, t_{s}\right) & =\varepsilon_{c s o} \beta_{s}\left(t-t_{s}\right), \\
\varepsilon_{c s o} & =\beta_{R H}\left[160+\beta_{s c}\left(90-f_{c}\right)\right] \times 10^{-6}, \\
\beta_{s}\left(t-t_{s}\right) & =\sqrt{\frac{\left(t-t_{s}\right)}{0.035\left(2 A_{c} / u\right)^{2}\left(t-t_{s}\right)}}, \\
\beta_{\mathrm{RH}} & =-1.55\left[1-\left(\frac{\mathrm{RH}}{100}\right) 3\right], \quad \text { for } 40 \% \leq \mathrm{RH} \leq 99 \%, \\
\beta_{\mathrm{RH}} & =1.25, \quad \text { for } \mathrm{RH}>99 \%,
\end{aligned}
$$


TABLE 4: Estimated parameters ( $a$ and $b$ ) for the modified theoretical shrinkage model and the resultant coefficient of determination $\left(R^{2}\right)$.

\begin{tabular}{lccc}
\hline Fly ash substitution level (\%) & $a$ & $b$ & $R^{2}$ \\
\hline 15 & 3381.01 & 24.48 & 0.99526 \\
25 & 3249.19 & 30.28 & 0.99572 \\
35 & 3636.34 & 30.28 & 0.99781 \\
45 & 3691.13 & 29.68 & 0.98908 \\
\hline
\end{tabular}

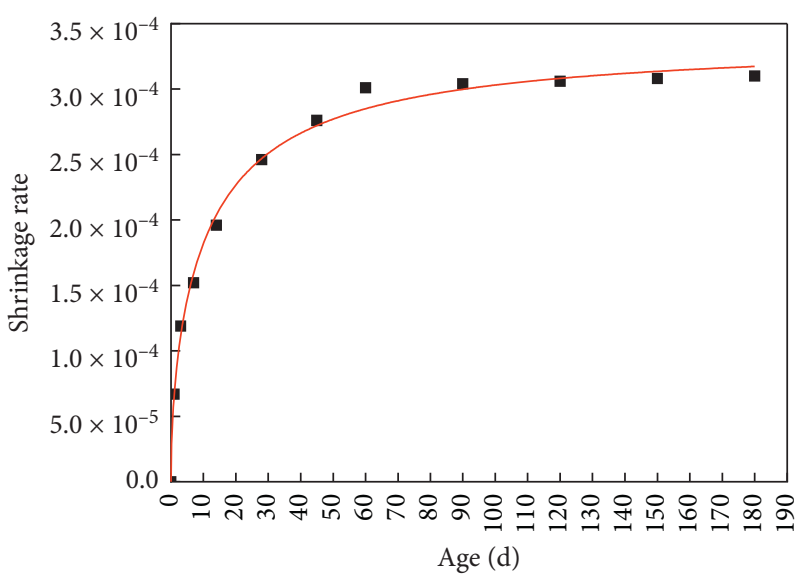

- Test date of $15 \%$ Fitting curve

(a)

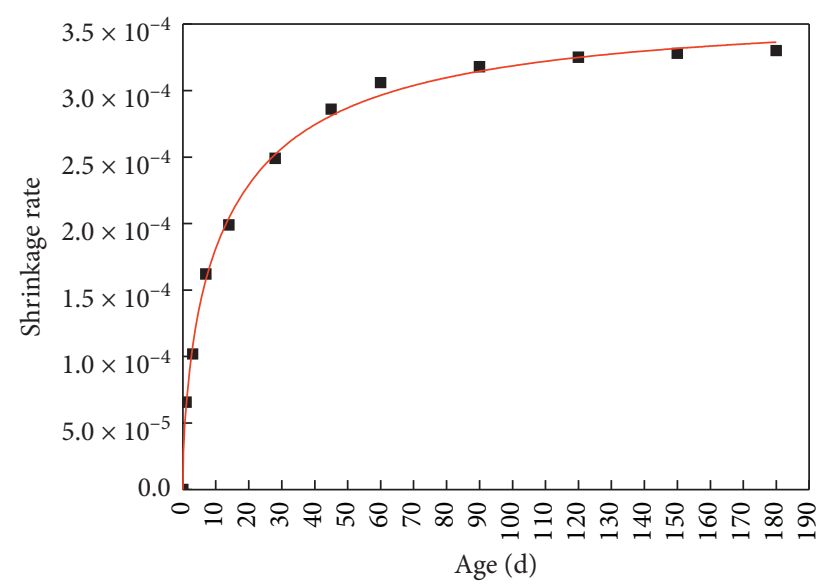

- Test date of $35 \%$ Fitting curve

(c)

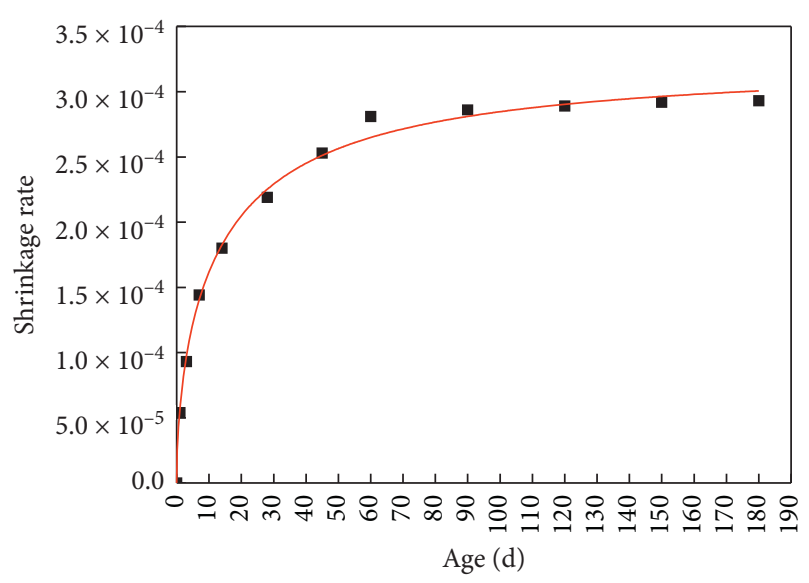

- Test date of $25 \%$

- Fitting curve

(b)

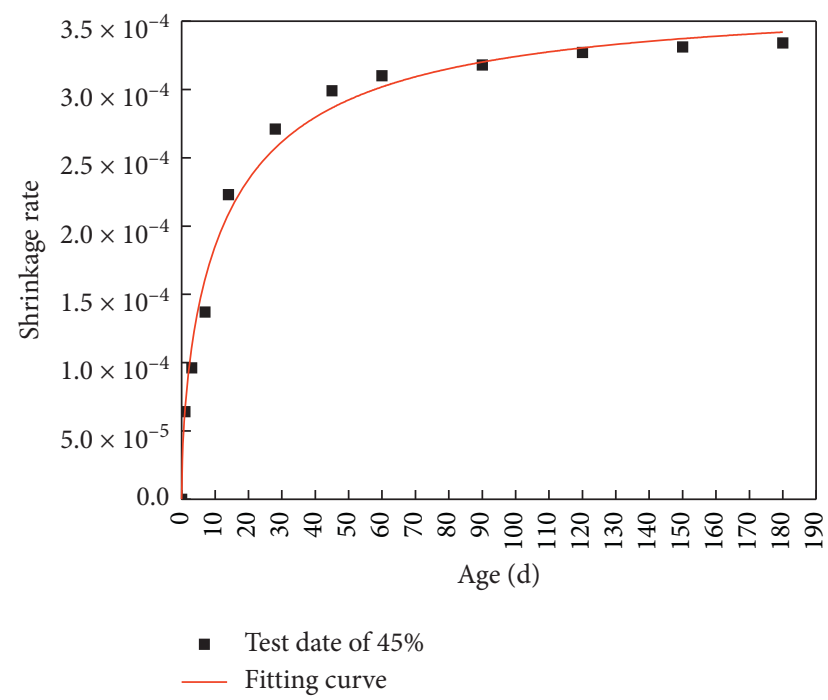

(d)

FIGURE 10: Goodness of fit for the modified theoretical shrinkage model developed in this study relative to the observed concrete shrinkage values obtained during experimentation: (a) $15 \%$ fly ash; (b) $25 \%$ fly ash; (c) $35 \%$ fly ash; (d) $45 \%$ fly ash.

where $t$ and $t_{s}$ are the times (d) of the concrete test and shrinkage initiation, respectively; $f_{c}$ is the compressive strength of the concrete $\left(\mathrm{N} / \mathrm{mm}^{2}\right) ; A_{c}$ is the cross-sectional area of the concrete $\left(\mathrm{mm}^{2}\right)$; and $u$ is the perimeter length of the concrete that is exposed to the atmosphere $(\mathrm{mm})$. The value of $\beta s c$ aries depending on the type of cement: $4=$ slow, hard cement; $5=$ fast, ordinary cement; and 8 =fast, hard, high-strength cement.
The above formula was appropriately simplified and modified based on this study's experimental data. Using the parameters $a$ and $b$ as substitutes for $\varepsilon_{c s o}$ and $0.035\left(2 A_{c} / u\right)^{2}$, respectively, equation (3) can be rewritten as follows:

$$
\varepsilon_{c s}\left(t, t_{s}\right)=a \cdot \sqrt{\frac{\left(t-t_{s}\right)}{b+\left(t-t_{s}\right)}},
$$


To validate this modified theoretical shrinkage model, we fit the model to the CFA shrinkage values observed during experimentation. Table 4 lists the estimated parameters, $a$ and $b$, and the resultant coefficient of determination $\left(R^{2}\right)$ for the concrete mixtures containing 15, 25, 35, and 45\% fly ash instead of fine aggregate. Figure 10 depicts the goodness of fit graphically. For each of the concrete mixtures containing fly ash instead of fine aggregate, the $R^{2}$ values approached or exceeded 0.99, indicating that the predicted values from the modified shrinkage model were consistent with the observed shrinkage values for the CFA with a high level of accuracy. These results suggest strong potential for this model in more broadly predicting shrinkage in CFA.

\section{Conclusions}

To support the energy industry's movement towards greener development in China by effectively utilizing coal combustion by-products, we investigated the use of fly ash instead of fine aggregate in concrete mixtures with a focus on concrete shrinkage. We performed a series of experiments varying only fly ash substitution levels $(0,15,25,35$, and $45 \%)$ initially and then varying the water-binder ratios and ambient humidities to determine changes in the concrete's drying and autogenous shrinkages. We then used these experimental results to evaluate common theoretical shrinkage models and subsequently develop a modified shrinkage model for application to concrete containing fly ash as fine aggregate. The key findings from this effort are as follows.

(i) The substitution of fly ash consistently decreased drying shrinkage relative to ordinary concrete (with $0 \%$ fly ash) over time. A substitution level of $25 \%$ optimally reduced drying shrinkage by $20.81 \%$. For autogenous shrinkage, higher fly ash substitution levels $(25,35$, and $45 \%)$ resulted in higher shrinkage rates relative to the ordinary concrete. Only the concrete mixture containing $15 \%$ fly ash instead of fine aggregate resulted in a lower shrinkage rate.

(ii) Drying and autogenous shrinkages developed at different rates over time. Drying shrinkage largely occurred before $28 \mathrm{~d}$, whereas autogenous shrinkage continued after $28 \mathrm{~d}$. At $28 \mathrm{~d}$, the drying shrinkage accounted for approximately $72-82 \%$ of the final shrinkage value for each concrete mixture, whereas the autogenous shrinkage accounted for approximately $51-67 \%$.

(iii) Based on the results of range analysis, ambient humidities demonstrated the greatest effect on shrinkage. Consistent with the single-factor analysis results, fly ash substitution levels also affected shrinkage because its volcanic ash and microaggregate effects decreased the concrete's internal porosity and limited concrete shrinkage. The waterto-binder ratio had a negligible effect. Shrinkage was minimized with $25 \%$ fly ash instead of fine aggregate and $100 \% \mathrm{RH}$. (iv) When determining the validity of conventional shrinkage models for CFA applications, the CEBFIP 90 model exhibited the highest prediction accuracy relative to the observed CFA shrinkage values. The ACI 209R and GL 2000 models both underestimated shrinkage in the early stages and overestimated shrinkage in the later stages. The modified theoretical shrinkage model (based on the conventional CEB-FIP 90 model) exhibited strong potential for predicting shrinkage in CFA. For each of the concrete mixtures containing fly ash instead of fine aggregate, the $R^{2}$ values approached or exceeded 0.99 , indicating that the predicted values from the modified shrinkage model were consistent with the observed shrinkage values for the CFA with a high level of accuracy.

(v) The results of this study advance the current state of knowledge regarding shrinkage in concrete mixtures containing varying volumes of fly ash instead of fine aggregate. In addition, this study resulted in the development of a modified theoretical shrinkage model that can be applied to predict the performance of similar concrete mixtures containing fly ash. By demonstrating potential for the effective utilization of fly ash in concrete mixtures instead of fine aggregate, these study results support the energy industry's movement towards greener development while ensuring environmental and public safety protections. Building upon these results, future research will consider other durability properties of CFA such as chloride ion erosion and impermeability.

\section{Data Availability}

The data used to support the findings of this study are available from the corresponding author upon request.

\section{Conflicts of Interest}

The authors declare no conflicts of interest.

\section{Authors' Contributions}

P. H. and M. M. were responsible for conceptualization; P. $\mathrm{H}$. was responsible for methodology and data curation,; D. Z., P. H., and M. M. were responsible for validation; M. M. was responsible for resources; D. Z. and P. H. were responsible for writing and original draft preparation; D. Z. and M. M. were responsible for writing and review and editing,; M. M. and Q. Y. were responsible for supervision and funding acquisition.

\section{Acknowledgments}

This study was supported by the National Natural Science Foundation of China (nos. 51568055 and 51768058), the Special Projects for Scientific and Technological Cooperation with Foreign Countries of Ningxia Province of China 
(2018BFH03002), and the Graduate Innovation Project of Ningxia University (GIP2019022). Their support was fundamental to this study.

\section{References}

[1] Y. Liu, Study on Durability of High Performance Pavement Concrete with Fly Ash, Chang'an University, Xi'an, China, 2005, in Chinese.

[2] X. Gong, H. Yao, D. Zhang, Y. Qiao, L. Li, and M. Xu, "Leaching characteristics of heavy metals in fly ash from a Chinese coal-fired power plant," Asia-Pacific Journal of Chemical Engineering, vol. 5, no. 2, pp. 330-336, 2010.

[3] Z. Han, Dissolution Kinetics of Alumina by Leaching Coal Fly Ash with Ammonium Hydrogen Sulfate, Shenyang University of Technology, Shenyang, China, 2016, in Chinese.

[4] T. Bilir, O. Gencel, and I. B. Topcu, "Properties of mortars with fly ash as fine aggregate," Construction and Building Materials, vol. 93, pp. 782-789, 2015.

[5] H. Ş. Arel and F. U. A. Shaikh, "Effects of fly ash fineness, nano silica, and curing types on mechanical and durability properties of fly ash mortars," Structural Concrete, vol. 19, no. 2, pp. 597-607, 2018.

[6] L. Varghese, V. V. L. Kanta Rao, and L. Parameswaran, "Study on high-volume unprocessed fly ash concrete with colloidal nanosilica under chloride exposure," ACI Materials Journal, vol. 116, no. 4, 2019.

[7] S. Uthaman, V. Vishwakarma, R. P. George et al., "Enhancement of strength and durability of fly ash concrete in seawater environments: synergistic effect of nanoparticles," Construction and Building Materials, vol. 187, 2018.

[8] X. Y. Wang, "Simulation for optimal mixture design of low$\mathrm{CO}_{2}$ high-volume fly ash concrete considering climate change and $\mathrm{CO}_{2}$ uptake," Cement and Concrete Composites, vol. 104, 2019.

[9] S. Dueramae, W. Tangchirapat, and C. Jaturapitakkul, "Strength and heat generation of concrete using carbide lime and fly ash as a new cementitious material without portland cement," Advanced Powder Technology, vol. 29, no. 3, pp. 672-681, 2018.

[10] I. Ignjatović, Z. Sas, J. Dragaš, J. Somlai, and T. Kovács, "Radiological and material characterization of high volume fly ash concrete," Journal of Environmental Radioactivity, vol. 168, 2017.

[11] H. Mihashi, "Characteristic points of AIJ recommendations for practice of crack control in reinforced concrete buildings (design and construction)," Concrete Journal, vol. 45, no. 2, pp. 9-15, 2007.

[12] K. Ishimaru, H. Mizuguchi, C. Hashimoto, T. Ueda, K. Fujita, and M. Ohmi, "Properties of concrete using copper slag and second class fly ash as a part of fine aggregate," Journal of the Society of Materials Science, Japan, vol. 54, no. 8, pp. 828-833, 2005.

[13] D. Zhang, M. Mao, S. Zhang, and Q. Yang, "Influence of stress damage and high temperature on the freeze-thaw resistance of concrete with fly ash as fine aggregate," Construction and Building Materials, vol. 229, 2019.

[14] M. Mao, J. Han, and W. Zhang, "Study on mechanical properties of fly ash fine aggregate concrete," Concrete, vol. 6, pp. 70-72, 2016, in Chinese.

[15] M. Mao, D. Zhang, Q. Yang, and W. Zhang, "Study of durability of concrete with fly ash as fine aggregate under alternative interactions of freeze-thaw and carbonation,"
Advances in Civil Engineering, vol. 2019, Article ID 4693893, 15 pages, 2019.

[16] D. Zhang, M. Mao, Q. Yang, W. Zhang, and P. Han, "Experimental investigation of the neutralisation of concrete with fly ash as fine aggregate in a freeze-thaw environment," Advances in Civil Engineering, vol. 2019, Article ID 6860293, 12 pages, 2019.

[17] T. Seo, M. Lee, C. Choi, and Y. Ohno, "Properties of drying shrinkage cracking of concrete containing fly ash as partial replacement of fine aggregate," Magazine of Concrete Research, vol. 62, no. 6, p. 427433, 2010.

[18] D. W. Mokarem, "Development of concrete shrinkage performance specifications," Virginia Polytechnic Institute and State University, Blacksburg, VA, USA, Doctoral Dissertation, 2002.

[19] M. Nastic, E. C. Bentz, O. S. Kwon, V. Papanikolaou, and J. Tcherner, "Shrinkage and creep strains of concrete exposed to low relative humidity and high temperature environments," Nuclear Engineering and Design, vol. 352, 2019.

[20] X. Zhang, Z. Liu, and F. Wang, "Autogenous shrinkage behavior of ultra-high performance concrete," Construction and Building Materials, vol. 226, 2019.

[21] J. Salimi, A. M. Ramezanianpour, and M. J. Moradi, "Studying the effect of low reactivity metakaolin on free and restrained shrinkage of high performance concrete," Journal of Building Engineering, vol. 28, 2019.

[22] K. Vardhan, R. Siddique, and S. Goyal, "Influence of marble waste as partial replacement of fine aggregates on strength and drying shrinkage of concrete," Construction and Building Materials, vol. 228, 2019.

[23] China Academy of Building Research, Standard for Test Method of Mechanical Properties on Ordinary Concrete (GB/T 50081-2002), China Architecture and Building Press, Beijing, China, 2002, in Chinese.

[24] China Academy of Building Research, Standard for Test Method of Long-Term Performance and Durability of Ordinary Concrete (GB/T 50082-2009), China Architecture and Building Press, Beijing, China, 2014, in Chinese.

[25] Z. Pan, B. Li, and Z. Lu, "Re-evaluation of CEB-FIP 90 prediction models for creep and shrinkage with experimental database," Construction and Building Materials, vol. 38, 2013.

[26] X. F. Wang, C. Fang, W. Q. Kuang, D. W. Li, N. X. Han, and F. Xing, "Experimental investigation on the compressive strength and shrinkage of concrete with pre-wetted lightweight aggregates," Construction and Building Materials, vol. 155, pp. 867-879, 2017.

[27] S. A. Al-Saleh, "Comparison of theoretical and experimental shrinkage in concrete," Construction and Building Materials, vol. 72, pp. 326-332, 2014.

[28] T. Hemalatha and A. Ramaswamy, "A review on fly ash characteristics-towards promoting high volume utilization in developing sustainable concrete," Journal of Cleaner Production, vol. 147, 2017.

[29] Q. X. Zhao, W. Sun, and C. W. Miu, "Effect and mechanism of interaction between fly ash proportion and water-binder ratio on the creep characteristics of high performance concrete," China Civil Engineering Journal, vol. 12, no. 42, pp. 76-82, 2009.

[30] M. Arezoumandi, J. S. Volz, C. A. Ortega, and J. J. Myers, "Shear behavior of high-volume fly ash concrete versus conventional concrete," Journal of Structural Engineering, vol. 141, no. 3, pp. 1506-1513, 2014, in Chinese.

[31] P. Yan and Z. Chen, "Autogenous shrinkage of fly ash concrete with different water binder ratios," Journal of the Chinese Ceramic Society, vol. 42, no. 5, pp. 585-589, 2014, in Chinese. 
[32] X. Li, P. Yan, and B. Aruhan, "Assessment method of hydration degree of cement in complex binder based on the calcium hydroxide content," Journal of the Chinese Ceramic Society, vol. 37, no. 10, pp. 1597-1601, 2009, in Chinese.

[33] C. Hao, M. Deng, L. Mo, and K. Liu, "Surface modification of fly ashes with carbide slag and its effect on compressive strength and autogenous shrinkage of blended cement pastes," Journal of Wuhan University of Technology-Materials Science Edition, vol. 27, no. 6, pp. 1149-1153, 2012.

[34] J.-L. Mo and X.-F. Wang, "Influence of fly ash on early-age cracking behavior of high-flowing concrete," Journal of Central South University of Technology, vol. 16, no. 2, pp. 312-319, 2009.

[35] C. Hao, M. Deng, L. Mo, and K. Liu, "Effect of pulverized fuel ashes on autogenous shrinkage and compressive strength of cement pastes," Journal of Building Materials and Structures, vol. 14 , no. 6 , pp. 746-751, 2011, in Chinese.

[36] R. Hela and L. Bodnarova, "Development of high-volume high temperature fly ash concrete (HVFAC)," Applied Mechanics and Materials, vol. 752-753, pp. 544-551, 2015. 